\title{
Solvation Dynamics of DCM in Human Serum Albumin
}

\author{
Samir Kumar Pal, Debabrata Mandal, Dipankar Sukul, Sobhan Sen, and \\ Kankan Bhattacharyya*
}

Physical Chemistry Department, Indian Association for the Cultivation of Science, Jadavpur, Calcutta 700 032, India

Received: July 1, 2000

\begin{abstract}
Solvation dynamics of 4-(dicyanomethylene)-2-methyl-6-(p-dimethylaminostyryl) $4 H$-pyran (DCM) in aqueous solution of a protein, human serum albumin (HSA), is studied using picosecond time-resolved emission spectroscopy. The solvation dynamics of DCM bound to HSA is found to be biexponential with one component of $600 \pm 100 \mathrm{ps}(25 \%)$ and a very long component of $10 \pm 1 \mathrm{~ns}(75 \%)$. This indicates that the motion of the water molecules in the vicinity of the protein is highly constrained.
\end{abstract}

\section{Introduction}

Chemistry in biological and confined environments is often strikingly different from that in bulk water. Water molecules confined in various biological and organized assemblies strongly influence the structure, function, and dynamics of biological systems. As a result, there is a vigorous current interest to unravel the behavior of water in various restricted environments. Dielectric relaxation time $\left(\tau_{\mathrm{D}}\right)$ of water is $8 \mathrm{ps},{ }^{1}$ while the solvation dynamics in bulk water occurs in subpicosecond time scale. ${ }^{2,3}$ However, in aqueous solutions proteins and many other organized assemblies exhibit an additional component of dielectric relaxation in the $10 \mathrm{~ns}$ time scale. ${ }^{4,5}$ According to the continuum theory, ${ }^{3}$ the solvation time, $\tau_{\mathrm{s}}$ is $\left(\epsilon_{\infty} / \epsilon_{\mathrm{S}}\right) \tau_{\mathrm{D}}$, where $\epsilon_{\infty}$ and $\epsilon_{\mathrm{s}}$ are, respectively, the high-frequency and static dielectric constant. Thus the observation of the $10 \mathrm{~ns}$ dielectric relaxation time immediately implies a component of solvation dynamics which is at least 3 orders of magnitude slower compared to bulk water. In recent years, several groups have reported dramatic retardation of the solvation dynamics of water in many organized assemblies such as proteins, ${ }^{6-8}$ DNA,${ }^{9}$ cyclodextrin, ${ }^{10}$ microemulsions, ${ }^{11-14}$ micelles, ${ }^{15}$ lipid vesicles, ${ }^{16}$ and sol-gel matrix. ${ }^{17}$ Interestingly, solvation dynamics at the water surface is observed to be very fast. ${ }^{18}$ Among the organized media mentioned above, study of the water molecules in the immediate vicinity of a protein is of fundamental importance to understand the behavior of biological water. Unfortunately, reports on the static and dynamic properties of the protein environment are still very scarce. Pierce and Boxer ${ }^{8 \mathrm{a}}$ and Bashkin et al. ${ }^{\mathrm{bb}}$ studied solvation dynamics in protein environments using dynamic Stokes shift and reported solvation times on the order of $10 \mathrm{~ns}$. Most recently, Fleming et al. ${ }^{6}$ and Beck et al. ${ }^{7}$ employed, respectively, three photon echo peak shift and transient grating spectroscopy to study the dynamic properties of the protein environment. One should, however, note that even the definition of the dielectric constant is not straightforward in the case of a protein because of the presence of many charged side groups. Recent simulations ${ }^{19}$ indicate that the static dielectric constant of a protein varies with position and depends quite strongly on what is taken into account explicitly in the model. Warshel et al. showed that excellent results are obtained if one assumes a

* Author to whom correspondence should be addressed. Fax: (91)-33473-2805. E-mail: pckb@mahendra.iacs.res.in.

\section{SCHEME 1: Structure of DCM}

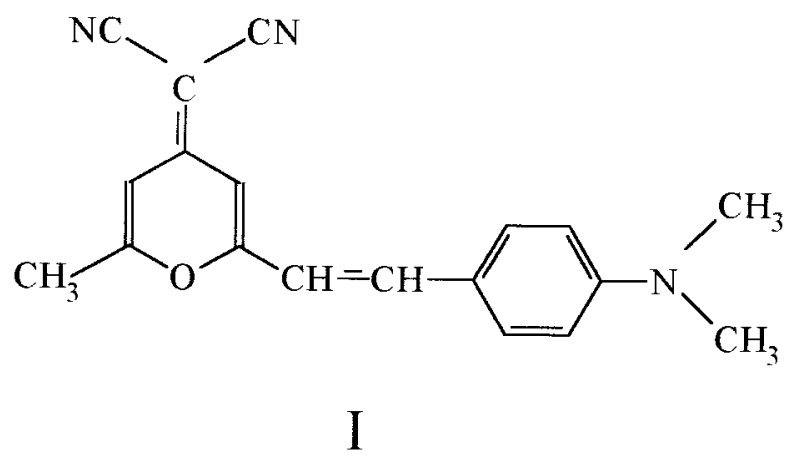

high local dielectric constant $\left(\epsilon_{\mathrm{s}} \geq 40\right)$ or a sigmoid function. ${ }^{19 \mathrm{a}, \mathrm{b}}$ Given these difficulties, Fleming et al. considered several dielectric continuum models to explain the solvation dynamics of eosin bound to lysozyme in aqueous solutions. ${ }^{6}$ They observed that eosin bound to lysozyme displays a very long component of $530 \mathrm{ps}$ which is absent in the solvation dynamics of free eosin in aqueous solution. ${ }^{6}$ This demonstrates that the water molecules in the immediate vicinity of the protein (lysozyme) is highly constrained.

In the present work, we report on the solvation dynamics of the laser dye 4-(dicyanomethylene)-2-methyl-6-( $p$-dimethylaminostyryl) $4 H$-pyran (DCM, Scheme 1 ), bound to human serum albumin (HSA) in aqueous solutions. Recent femtosecond studies show that in methanol DCM exhibits an inertial component of solvation dynamics on the $100 \mathrm{fs}$ time scale and another component of a few picoseconds. ${ }^{20,21}$ The main advantage of DCM as a probe for aqueous protein solutions is the fact that DCM is completely insoluble in water. The insolubility of DCM in water makes it a better candidate to bind to the hydrophobic region of the protein. Further, once DCM binds to a protein, the complications due to contribution of free DCM in bulk water is completely avoided.

\section{Experimental Section}

DCM (laser grade, Exciton) and HSA (Sigma) were used as received. For recording steady-state absorption and emission spectra, we used, respectively, a JASCO 7850 absorption spectrophotometer and a Perkin-Elmer 44B fluorimeter. For 


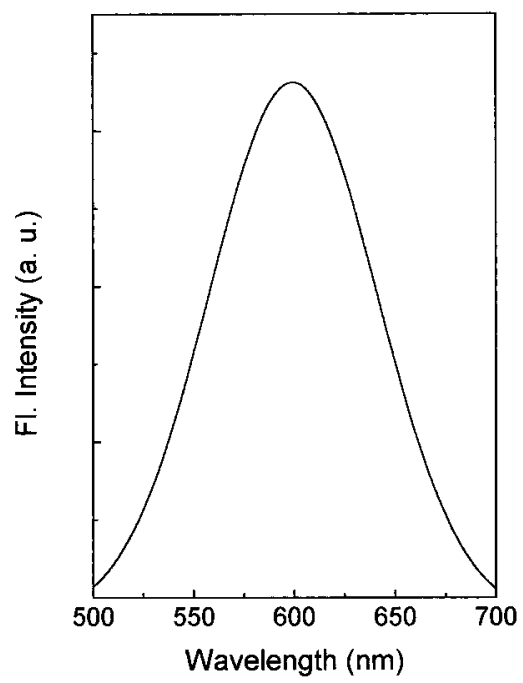

Figure 1. Emission spectrum of DCM in $70 \mu \mathrm{M}$ HSA in aqueous tris buffer.

time-resolved studies, the sample was excited at $300 \mathrm{~nm}$ with the second harmonic of a cavity dumped rhodamine $6 \mathrm{G}$ dye laser (Coherent 702-1) pumped by a cw mode locked Nd:YAG laser (Coherent Antares 76s). The emission was detected at magic angle polarization, using a Hamamatsu MCP photomultiplier (2809U). The full width at half-maximum of the instrument response at $300 \mathrm{~nm}$ is $\approx 50 \mathrm{ps}$. Fluorescence decays were deconvoluted using a global lifetime analysis software (PTI). The sample was prepared as follows. To $1.5 \mathrm{~mL}$ of 70 $\mu \mathrm{M}$ HSA aqueous solution in tris buffer of $\mathrm{pH} 7.4,30 \mu \mathrm{L}$ of a methanol solution of DCM was injected using a microliter syringe. In the absence of HSA, if a methanolic solution of DCM is injected in aqueous tris buffer, DCM is immediately precipitated. The contribution of the very little (2\%) amount of methanol may be neglected, as most of it is likely to evaporate at room temperature. Further, since in methanol DCM exhibits a very fast solvation dynamics in a few picoseconds or faster time scale, ${ }^{20,21}$ the very long components (600 ps and $10 \mathrm{~ns}$ ) detected in this work cannot be due to traces of methanol.

\section{Results}

3.1. Steady-State Spectra. In a nonpolar medium such as $n$-heptane, DCM exhibits an absorption maximum around 450 $\mathrm{nm}$ and a very weak emission band with maximum at $530 \mathrm{~nm} .^{12 \mathrm{a}}$ When a methanolic solution of DCM is injected into a buffered aqueous solution of HSA, the DCM molecules bind to HSA. The protein-bound DCM molecules exhibit marked red shift of absorption and excitation maximum to $480 \mathrm{~nm}$ and a strong emission band with maximum at $600 \mathrm{~nm}$ and quantum yield of 0.66 (Figure 1). Since DCM is insoluble in water, the steadystate spectral properties of DCM bound to HSA, could not be compared with those of DCM in water. With increase in solvent polarity, the emission maximum of DCM displays a red shift from $530 \mathrm{~nm}$ in $n$-heptane to $620 \mathrm{~nm}$ in methanol. ${ }^{12 \mathrm{a}, 20-21}$ It is evident that the observed emission maximum of DCM bound to HSA is similar to that of DCM in highly polar solvents. ${ }^{20-21}$

3.2. Time-Resolved Studies. The fluorescence decays of DCM bound to HSA show a significant dependence on the emission wavelength. At the blue end of the emission spectrum, only a fast decay is observed while at the red end the decay is preceded by a distinct rise (Figure 2). Such a wavelength dependence clearly indicates that, in the protein environment, the DCM molecules exhibit solvation dynamics. From the

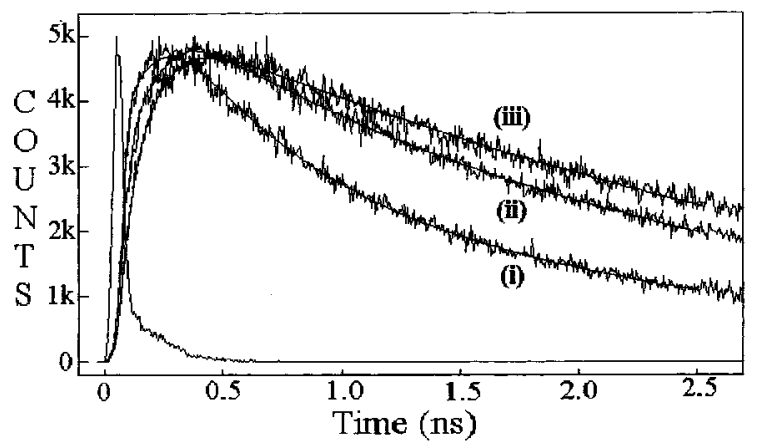

Figure 2. Fluorescence decays of DCM in $70 \mu \mathrm{M}$ HSA in aqueous tris buffer at (i) $520 \mathrm{~nm}$, (ii) $600 \mathrm{~nm}$, (iii) $685 \mathrm{~nm}$.

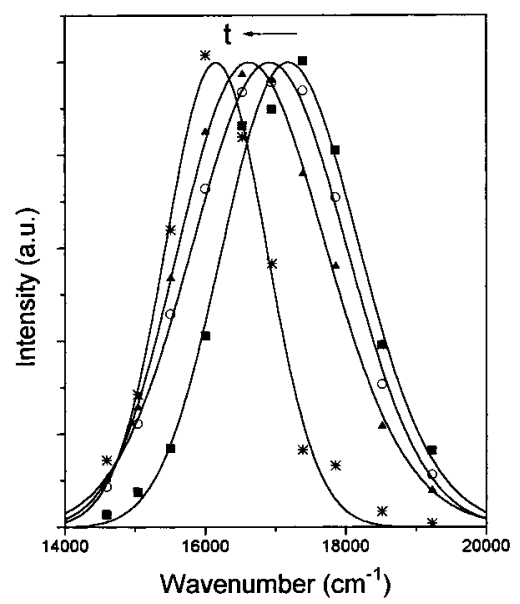

Figure 3. Time-resolved emission spectra of DCM in $70 \mu \mathrm{M}$ HSA in aqueous tris buffer at 0 ps $(\boldsymbol{\square}), 1000$ ps $(\bigcirc), 4000$ ps (A), $25000\left(^{*}\right)$.

parameters of best fit to the emission decays and using the steady-state emission spectra, time-resolved emission spectra (TRES, Figure 3) of DCM in HSA have been constructed following the procedure described by Fleming and Maroncelli. ${ }^{3 \mathrm{c}}$ The solvation dynamics is described by the decay of the response function $C(t)$ which is defined as

$$
C(t)=\frac{v(t)-v(\infty)}{v(0)-v(\infty)}
$$

where $v(0), v(t)$, and $v(\infty)$ denote the observed emission energies (frequencies) at time zero, $t$, and infinity. The decay of $C(t)$ for DCM bound to HSA, is shown in Figure 4. The decay parameters of $C(t)$ are summarized in Table 1. The total Stokes shift, $\Delta v=v(0)-v(\infty)$, of DCM in HSA is found to be 1030 $\mathrm{cm}^{-1}$. The decay of $C(t)$ is found to be biexponential with one component of $600 \pm 100$ ps $(25 \%)$ and a very long component of $10 \pm 1 \mathrm{~ns}(75 \%)$.

\section{Discussion}

The most interesting finding of this work is that the decay of $C(t)$ for DCM bound to HSA is biexponential with one component of $600 \pm 100$ ps $(25 \%)$ and a very long component of $10 \pm 1 \mathrm{~ns}$. In the three photon echo peak shift (3PEPS) study of eosin bound to lysozyme, Fleming et al. ${ }^{6}$ detected a long component of 530 ps when they fitted the decay up to $1 \mathrm{~ns}$. This component contributes only about $8 \%$ to the total solvation. ${ }^{6}$ Berg et al. ${ }^{9}$ on the other hand, reported that for coumarin 480 covalently bound to DNA, the decay of $C(t)$ is biexponential with two components of 300 ps (47\%) and 13.4 ns (53\%), respectively. It is evident that the decay components of $C(t)$ 


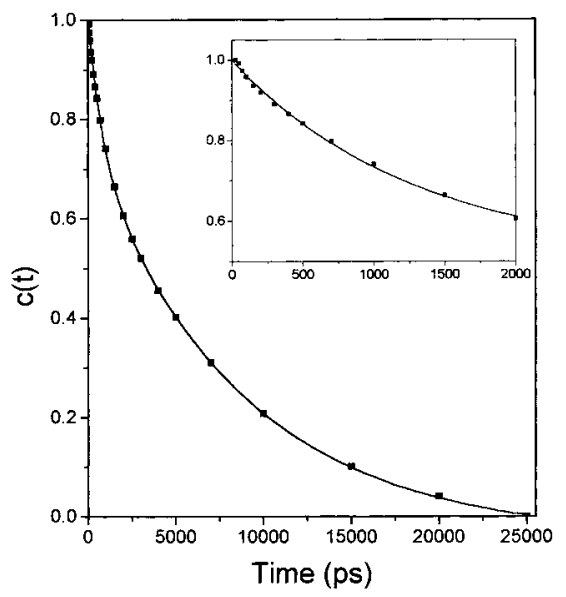

Figure 4. Decay of response function, $C(t)$, of DCM in $70 \mu \mathrm{M}$ HSA in aqueous tris buffer. The points denote the actual values of $C(t)$ and the solid line denotes the best fit to a biexponential decay. The decay of the initial portion is given in the inset.

TABLE 1: Decay Parameters of $C(t)$ of DCM in $70 \mu \mathrm{M}$ HSA in Aqueous Tris Buffer

\begin{tabular}{ccccc}
\hline$\Delta v\left(\mathrm{~cm}^{-1}\right)$ & $a_{1}$ & $\tau_{1}(\mathrm{ps})$ & $a_{2}$ & $\tau_{2}(\mathrm{~ns})$ \\
\hline 1030 & 0.25 & $600 \pm 100$ & 0.75 & $10 \pm 1$
\end{tabular}

observed in the present work is similar to those reported by Fleming et al. ${ }^{6}$ and Berg et al. ${ }^{9}$

The total Stokes shift $\left(\Delta v=1030 \mathrm{~cm}^{-1}\right)$ detected for proteinbound DCM, is smaller than those of DCM in methanol (3800 $\left.\mathrm{cm}^{-1}\right)$ and in ethylene glycol $\left(2400 \mathrm{~cm}^{-1}\right)$ reported in previous femtosecond studies. ${ }^{20,21}$ In our apparatus of time resolution $\sim 50$ ps, we are obviously missing a very large part of the solvation which occurs in the femtosecond time scale in the protein environment. ${ }^{20,21}$ The amount of solvation missed in a picosecond setup may, in principle, be calculated using a method outlined by Fee and Maroncelli. ${ }^{3 \mathrm{~d}}$ Unfortunately, using our rhodamine $6 \mathrm{G}$ dye laser, we excited the sample at a wavelength $300 \mathrm{~nm}$ which is very much shifted from the absorption maximum of protein-bound DCM $(480 \mathrm{~nm})$. For this wavelength of excitation, the various stages of curve fitting described by Fee and Maroncelli, are unlikely to give a good estimate of the amount of solvation missed. Nevertheless, it is unmistakable that the solvation dynamics of DCM molecules bound to HSA exhibits a decay component which is very much slower than the subpicosecond components observed for DCM in methanol $^{20,21}$ or other probes in water. ${ }^{2,10 a}$

Since DCM is insoluble in water the possibility of DCM staying in bulk water may be ruled out. In a hydrocarbon solvent, the emission quantum yield of DCM is extremely low $(0.01)$ and the lifetime is very short ( $<50 \mathrm{ps}) .{ }^{12 a}$ Further, in $n$-heptane the emission maximum of DCM is very much blue shifted to $530 \mathrm{~nm}$ and the decay does not exhibit a wavelength dependence. ${ }^{12 \mathrm{a}}$ In the case of DCM in HSA, the observed emission maximum at $600 \mathrm{~nm}$ and the wavelength dependence of the emission decays suggest that in the protein environment the DCM molecules do not reside in a "dry" and nonpolar hydrocarbon-like environment. The observed solvation dynamics appears to be due exclusively to the DCM molecules in a polar environment in which the motion of the polar entities (i.e., water) is highly constrained.

As a first approximation, one can use the continuum theory to rationalize the results. $\epsilon_{\infty}$ of the water molecules bound to proteins may be assumed to be same as that of water, i.e., $5,^{3}$ while following Warshel et al. ${ }^{19 \mathrm{~b}} \epsilon_{\mathrm{s}}$ may be taken as $\sim 40$. Then using a dielectric relaxation time $\left(\tau_{\mathrm{D}}\right)$ in $10 \mathrm{~ns},{ }^{4,5}$ one im- mediately calculates a solvation time of $(5 / 40) \times 10 \mathrm{~ns}$, i.e., 1250 ps. This crude estimate is somewhat in between the two decay components of $600 \mathrm{ps}$ and $10 \mathrm{~ns}$.

It is obvious that the observed components of $600 \mathrm{ps}$ and 10 ns are too slow to be due to any vibrational motion of either the probe or the environment. At this stage it is rather difficult to ascertain the origin of the slow components of the solvation dynamics. It seems that such a long component may be due to the chemical exchange process between "bound" and "free" water molecules as suggested in a recent theoretical model by Nandi and Bagchi. ${ }^{5}$ A similar exchange mechanism is also indicated in ${ }^{17} \mathrm{O}$ nuclear magnetic relaxation dispersion (NMRD) studies, ${ }^{4 c, 22 a, b}$ nuclear Overhauser effect studies, ${ }^{22 c}$ and reaction path calculations ${ }^{22 \mathrm{~d}}$ of aqueous protein solutions. According to the NMRD studies, the relaxation or residence time of proteinbound water molecules span a wide range of time scales from nanosecond to several microseconds. ${ }^{22 \mathrm{a}-\mathrm{b}}$ It is proposed that in bulk, motion of water is cooperative in nature involving an extended hydrogen-bond network. ${ }^{22 b}$ For a protein-bound water, the hydrogen-bond network gets seriously disrupted, and in the extreme case of a water molecule buried deep inside a protein, it may not be hydrogen-bonded to another water molecule at all, and instead, remains hydrogen-bonded to the neighboring polar groups of the protein molecule. ${ }^{22 \mathrm{~b}}$ For a detailed understanding of the dynamics of water molecules bound to proteins it is necessary to know the number of water molecules near the probe (i.e., DCM, in the present case) as well as the structure of the system. Unfortunately, for a noncovalently bound probe (e.g., DCM bound to HSA or eosin bound to lysozyme ${ }^{6}$ ) the exact location of the probe is uncertain. Future studies with solvation probes covalently attached to specified sites within a protein and detailed structural information should reveal more detailed information of dynamics of protein-bound water.

The 600 ps and 10 ns components may also arise because of the different relaxation times of water molecules at different regions of protein, as indicated by the NMRD studies. ${ }^{22 a-b}$ Another possibility is that the 600 ps component is due to bound water molecules and the very long $10 \mathrm{~ns}$ component is due to relaxation of segments of a protein containing many polar groups. ESR studies of lipid chains indicate that the chain dynamics occurs in $100 \mathrm{~ns}$ time scale. ${ }^{23}$ Though the $10 \mathrm{~ns}$ component of solvation dynamics is at least one order of magnitude slower than the $100 \mathrm{~ns}$ component of chain dynamics, ${ }^{23}$ one cannot rule out the possibility that the $10 \mathrm{~ns}$ component is due to motion of a segment of the protein.

\section{Conclusion}

The present work demonstrates that the solvation dynamics of DCM molecules which occurs in subpicosecond time scale in polar solvents such as methanol, is slowed down significantly when DCM is transferred to the hydrophobic interior of a protein, HSA. It is observed that in the protein environment, solvation dynamics of DCM is biexponential with one component of $600 \pm 100 \mathrm{ps}(25 \%)$ and a very long component of 10 $\pm 1 \mathrm{~ns}(75 \%)$. The slow solvation dynamics is consistent with the previous dielectric relaxation studies in proteins ${ }^{4,5}$ and solvation dynamics studies in protein ${ }^{6}$ and in DNA. ${ }^{9}$ The present study demonstrates that the biological water molecules present in the immediate vicinity of a protein are substantially slower than ordinary water molecules.

Acknowledgment. Thanks are due to Council of Scientific and Industrial Research (CSIR) for generous research grants. 
S.K.P., D.M., D.S., and S.S. thank CSIR for awarding fellowships. K.B. thanks Professor B. Bagchi for many stimulating discussions.

\section{References and Notes}

(1) Kaatze, U. Chem. Phys. Lett. 1993, 203, 1.

(2) (a) Jarzeba, W.; Walker, G. C.; Johnson, A. E.; Kahlow, M. A.; Barbara, P. F. J. Phys. Chem. 1988, 92, 7039. (b) Jimenez, R.; Fleming, G. R.; Kumar, P. V.; Maroncelli, M. Nature 1994, 369, 471.

(3) (a) Castner, E. W., Jr.; Maroncelli, M. J. Mol. Liq. 1998, 77, 1. (b) Stratt, R. M.; Maroncelli, M. J. Phys. Chem. 1996, 100, 12981. (c) Maroncelli, M.; Fleming, G. R. J. Chem. Phys. 1987, 86, 6221. (d) Fee, R. S.; Maroncelli, M. Chem. Phys. 1994, 183, 235.

(4) (a) Mashimo, S.; Kuwabara, S.; Yagihara, S.; Higasi, K. J. Phys. Chem. 1987, 91, 6337. (b) Fukuzaki, M.; Miura, N.; Sinyashiki, N.; Kunita, D.; Shiyoya, S.; Haida, M.; Mashimo, S. J. Phys. Chem. 1995, 99, 431. (c) Belton, P. S. J. Phys. Chem. 1995, 99, 17061. (d) Telgmann, T.; Kaatze, U. J. Phys. Chem. A 1998, 102, 7758 and 7766. (d) D'Angelo, M.; Fioretto, D.; Onori, G.; Palmieri, L.; Santucci, A. Phys. Rev. E 1996, 54, 993.

(5) (a) Nandi, N.; Bagchi, B. J. Phys. Chem. B 1997, 101, 10954. (b) Nandi, N.; Bagchi, B. J. Phys. Chem. A 1998, 102, 8217. (c) Nandi, N.; Bhattacharyya, K.; Bagchi, B. Chem. Rev. 2000, 100, 2013. (d) Bhattacharyya, K.; Bagchi, B. J. Phys. Chem. A 2000, 104, 10603.

(6) Jordandies, X. J.; Lang, M. J.; Song, X.; Fleming, G. R. J. Phys. Chem. B 1999, 103, 7995.

(7) Homoelle, B. J.; Edington, M. D.; Diffey, W. M.; Beck, W. F. J. Phys. Chem. B 1998, 102, 3044.

(8) (a) Pierce, D. W.; Boxer, S. G. J. Phys. Chem. 1992, 96, 5560. (b) Bashkin, J. S.; McLendon, G.; Mukamel, S.; Marohn, J. J. Phys. Chem. 1990, $94,4757$.

(9) Brauns, E. B.; Madaras, M. L.; Coleman, R. S.; Murphy, C. J.; Berg, M. A. J. Am. Chem. Soc. 1999, 121, 11644.

(10) (a) Vajda, S.; Jimenez, R.; Rosenthal, S. J.; Fidler, V.; Fleming,

G. R.; Castner, E. W., Jr. J. Chem. Soc., Faraday Trans. 1995, 91, 867. (b)

Nandi, N.; Bagchi, B. J. Phys. Chem. 1996, 100, 13914. 3775 .

11) Lundgren, I. S.; Heitz, M. P.; Bright, F. V. Anal. Chem. 1995, 67,

(12) (a) Pal, S. K.; Mandal, D.; Sukul, D.; Bhattacharyya, K. Chem. Phys. Lett. 1999, 312, 178. (b) Das, S.; Datta, A.; Bhattacharyya, K. J. Phys. Chem. A 1997, 101, 3299. (c) Mandal, D.; Datta, A.; Pal, S. K.;
Bhattacharyya, K. J. Phys. Chem. B 1998, 102, 9070.

(13) (a) Willard, D. M.; Riter, R. E.; Levinger, N. E. J. Am. Chem. Soc. 1998, 120, 4151. (b) Riter, R. E.; Undiks, E. P.; Levinger, N. E. J. Am. Chem. Soc. 1998, 102, 2705. (c) Riter, R. E.; Undiks, E. P.; Kimmel, J. R.; Pant, D. D.; Levinger, N. E. J. Phys. Chem. B 1998, 102, 7931. (d) Shirota, H.; Horie, K. J. Phys. Chem. B 1999, 103, 1437.

(14) (a) Cho, C. H.; Chung, M.; Lee, J.; Nguyen, T.; Singh, S. Vedamuthu, M.; Yao, S.; Zhu, S.-B.; Robinson, G. W. J. Phys. Chem. B 1995, 99, 7806. (b) Zhu, S.-B.; Singh, S.; Robinson, G. W. Adv. Chem. Phys. 1994, 85, 627.

(15) (a) Sarkar, N.; Datta, A.; Das, S.; Bhattacharyya, K. J. Phys. Chem. 1996, 100, 15483. (b) Datta, A.; Mandal, D.; Pal, S. K.; Bhattacharyya, K. J. Mol. Liq. 1998, 77, 121.

(16) Datta, A.; Pal, S. K.; Mandal, D.; Bhattacharyya, K. J. Phys. Chem. $B$ 1998, 102, 6114 .

(17) Pal, S. K.; Sukul, D.; Mandal, D.; Sen, S.; Bhattacharyya, K. J. Phys. Chem. B 2000, 104, 2613.

(18) Zimdars, D.; Eisenthal, K. B. J. Phys. Chem. B 1999, 103, 10567.

(19) (a) Aqvist, A.; Warshel, A. Chem. Rev. 1993, 93, 2423. (b) King, G.; Lee, F. S.; Warshel, A. J. Chem. Phys. 1991, 95, 4366. (c) Simonson, T. J. Am. Chem. Soc. 1998, 120, 8452. (d) Smith, P. E.; Brunne, R. M.; Mark, A. E.; Van Gunsteren, W. F. J. Phys. Chem. 1993, 97, 2009.

(20) (a) Gustavsson, T.; Baldacchino, G.; Mialocq, J.-C.; Pommeret, S. Chem. Phys. Lett. 1995, 236, 587. (b) van der Meulen, P.; Zhang, H.; Jonkman, M.; Glasbeek, M. J. Phys. Chem. 1996, 100, 5367. (c) Zhang, H.; Jonkman, A. M.; van der Meulen, P.; Glasbeek, M. Chem. Phys. Lett. 1994, 224, 551. (d) Jonkman, M.; van der Meulen, P.; Zhang, H.; Glasbeek, M. Chem. Phys. Lett. 1996, 256, 21.

(21) (a) Easter, D. C.; Baronavski, A. P. Chem. Phys. Lett. 1993, 201, 153. (b) Mayer, M.; Mialocq, J.-C. Opt. Commun. 1987, 64, 264. (c) HsingKang, Z.; Ren-Lan, M.; Er-pin, N.; Chu, G. J. Photochem. 1985, 29, 397. (d) Retting, W.; Majenz, W. Chem. Phys. Lett. 1989, 154, 335. (e) Gilabert, E.; Lapouyade, R.; Rulliere, C. Chem. Phys. Lett. 1988, 145, 262.

(22) (a) Denisov, V. P.; Venu, K.; Peters, J.; Horlein, H. D.; Halle, B. J. Phys. Chem. B 1997, 101, 9380. (b) Denisov, V. P.; Halle, B. Faraday Discuss. 1996, 103, 227. (c) Otting, G.; Liepinish, E. Acc. Chem. Res. 1995, 28, 171. (d) Fischer, S.; Verma, C. S.; Hubbard, R. J. Phys. Chem. B 1998 , 102, 1797.

(23) (a) Cassol, R.; Ge, M.-T.; Ferrarini, A.; Freed, J. H. J. Phys. Chem. $B$ 1997, 101, 8782. (b) Sung-Suh, M. M.; Kevan, L. J. Phys Chem. A 1997, $101,1414$. 